\title{
Advances in Aircraft Brakes and Tires
}




\title{
Other SAE books of interest:
}

No Fault Found: The Search for the Root Cause

By S. Khan, I.K. Jennions, P. Phillips and C. Hockley

(Product Code: R-441)

\author{
Ice Accretion and Icing Technologies \\ By R. J. Flemming \\ (Product Code: PT-163)
}

\section{Spotlight on Design: Sensors, Fluid Measurements and Avionics}

(Product Code: SOD-007/1)

\author{
For more information or to order a book, contact: \\ SAE INTERNATIONAL \\ 400 Commonwealth Drive \\ Warrendale, PA 15096 \\ Phone: +1.877.606.7323 (U.S. and Canada only) \\ or +1.724 .776 .4970 (outside U.S. and Canada) \\ Fax: +1.724.776.0790 \\ Email: CustomerService@sae.org \\ Website: books.sae.org
}




\title{
Advances in Aircraft Brakes and Tires
}

\author{
By R. Kyle Schmidt
}

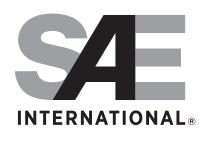

Warrendale, Pennsylvania, USA 


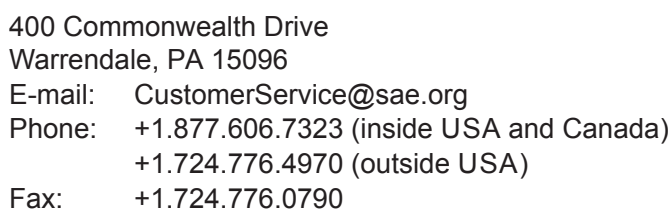

Copyright (c) 2015 SAE International. All rights reserved.

Printed in the United States of America

No part of this publication may be reproduced, stored in a retrieval system, distributed, or transmitted, in any form or by any means without the prior written permission of SAE International. For permission and licensing requests, contact SAE Permissions, 400 Commonwealth Drive, Warrendale, PA 15096-0001 USA; e-mail: copyright@sae.org; phone: 724-772-4028; fax: 724-7729765.

Library of Congress Catalog Number 2015947584

SAE Order Number PT-171

http://dx.doi.org/10.4271/pt-171

Information contained in this work has been obtained by SAE International from sources believed to be reliable. However, neither SAE International nor its authors guarantee the accuracy or completeness of any information published herein and neither SAE International nor its authors shall be responsible for any errors, omissions, or damages arising out of use of this information. This work is published with the understanding that SAE International and its authors are supplying information, but are not attempting to render engineering or other professional services. If such services are required, the assistance of an appropriate professional should be sought.

ISBN-Print 978-0-7680-8236-4

ISBN-PDF 978-0-7680-8249-4

ISBN-epub 978-0-7680-8251-7

ISBN-prc 978-0-7680-8250-0

To purchase bulk quantities, please contact

SAE Customer Service

e-mail: CustomerService@sae.org

phone: +1.877.606.7323 (inside USA and Canada)

+1.724 .776 .4970 (outside USA)

fax: +1.724 .776 .0790$

Visit the SAE Bookstore at

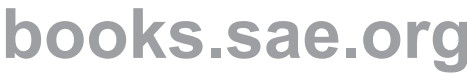




\section{Table of Contents}

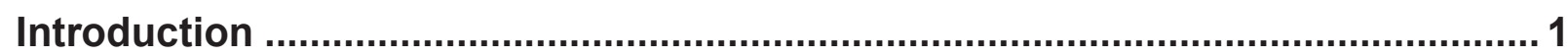

Tires

Mechanical Properties of Radial-Ply Aircraft Tires (2005-01-3438) ..............................5

Hydroplaning of H-Type Aircraft Tires (2004-01-3119) ...............................................19

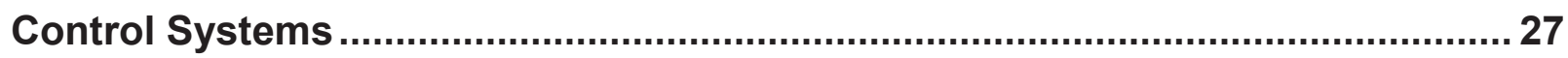

A Longitudinal Slip Tire Model for Brake Control Systems: Features and Uses in Simulation, Control Synthesis, and Stability Analysis (2002-01-2949) ........................29

A Sliding Mode Observer Based ABS for Aircraft and Land Vehicles

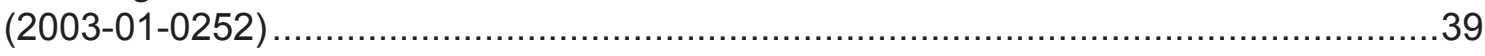

Braking Systems with New IMA Generation (2011-01-2662) ......................................47

Brakes

Predicting Landing Gear Carbon Brake Vibration and Performance via Subscale

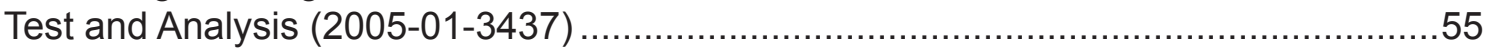

Adsorption and Desorption Effects on Carbon Brake Material Friction and Wear

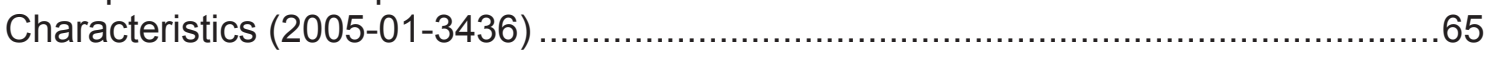

Reducing Aircraft Brake Squeal with a Damped Brake-Rod (2000-01-5599)...............83

Asymmetric Approach in Solving Aircraft Brake Vibration (2002-01-2948)...................87

The Effect of Wear Groove on Vibration and Noise of Aircraft Brakes: Theoretical

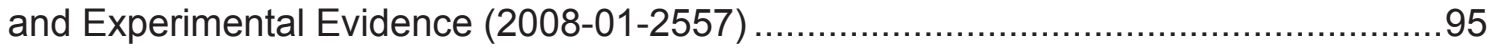

Aircraft Electric Brakes - Technical Development (2002-01-2946) ............................ 103

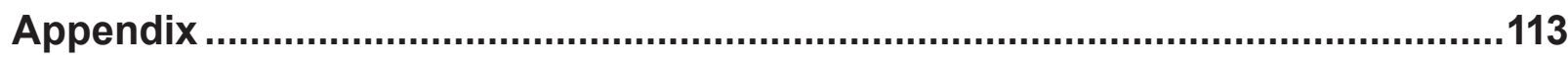

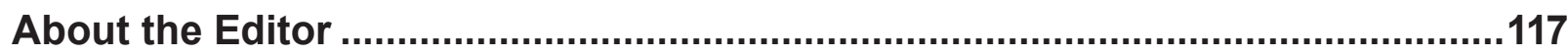

